\title{
Study of Leukocytes level as a prognostic marker in patients with organophosphate poisoning
}

\author{
Sapkota $\mathrm{S}^{1 *}$, Khanal A2, Maskey A ${ }^{1}$, Paudel N ${ }^{1}$, Paudel R ${ }^{3}$ \\ ${ }^{1}$ Department of Internal Medicine, Manipal College of Medical Sciences \\ ${ }^{2}$ Department of Internal Medicine (FCPS trainee), Kathmandu Medical College \\ ${ }^{3}$ Department of Pediatrics, Manipal College of Medical Sciences
}

\section{DOI Name}

http://dx.doi.org/10.3126/jaim.v7i1.19576

\section{Keywords}

Leukocytes, organophosphates, poisoning, prognostic factors

\section{Citation}

Sapkota S, Khanal A, Maskey A, Paudel N, Paudel R. Study of Leukocytes level as a prognostic marker in patients with organophosphate poisoning. Journal of Advances in Internal Medicine 2017;06(01):6-10.

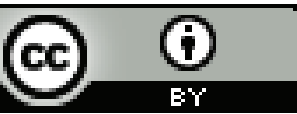

This work is licensed under a Creative Commons Attribution 3.0 Unported License.

\begin{abstract}
Background : Elevated leukocytes level at admission is a common finding in patients with organophosphates poisoning. It has been suggested as a prognostic marker. Since early leukocytosis is frequent and mulifactorial in origin, we hypothesized that leukocytes level after 24 hours may be a better predictor of mortality.
\end{abstract}

Objectives : To evaluate the prognostic value of leukocytes level at admission; and at 24-48 hours in organophosphate poisoning.

Methods : A hospital based, retrospective, cohort study of patients with organophosphate poisoning was conducted in Manipal Teaching Hospital, Pokhara, Nepal. After obtaining ethical clearance from Institutional research committee, records of patients presenting with poisoning were reviewed. 103 records were considered eligible for study. Relevant data were collected in a preformed pro forma and statistical analyses were carried out.

Results : Mean age of 103 participant was 29.4 (SD=11.68). Out of them 57\% were females and $43 \%$ were males. T-test was applied to test for difference in age, blood pressure, leukocytes at admission, at 24-48 hrs and blood sugar of those patients with different outcomes. Except for leukocytes levels at admission $(p=0.104)$, statistically significant difference was seen in all other parameters $(p<0.001)$. Logistic regression analysis indicated that leukocytes levels at $24-48 \mathrm{hrs}(B=0.002, p=0.013)$ is a better predictor of mortality than leukocytes levels at admission $(B=0.000, p=0.034)$.

Conclusion : Our analysis supports the hypothesis that leukocytes level at 24-48 hrs is a better predictor of mortality than leukocytes level at admission. However further study with a prospective design is recommended to confirm or refute the hypothesis.

\section{INTRODUCTION}

Organophosphates are highly toxic compounds commonly used as insecticides and pesticides which present a serious threat in terms of human intoxication leading to complex symptoms and increase in mortality rate. ${ }^{1}$ High mortality due to organophosphates(OP) is usually ascribed to delay in diagnosis and improper treatment. ${ }^{2}$ Some of the accepted prog- nostic factors for OP poisoning are acetyl-cholinesterase activity $^{3}$, Acute Physiology and Chronic Health Evaluation(APACHE) score, Simplified Acute Physiology Score(SAPS) ${ }^{4}$, Bardin's

\footnotetext{
* Corresponding author Dr. Subash Sapkota Lecturer, Internal medicine Manipal College of Medical Sciences Fulbari-11, Pokhara, Nepal Email: subash76@gmail.com
} 
grading of severity ${ }^{2,5}$ and Peradeniya organophosphorus poisoning (POP) scale. ${ }^{6}$

One of the commonest laboratory findings in patients with OP poisoning at admission is the elevation of leukocytes levels., 8 Amanvermez et al. ${ }^{5}$ found that leukocytes levels are not only elevated at admission, but it also had prognostic value for mortality.

Leukocytosis at admission is considered to be due to various factors like a) increase in sympathetic activity precipitating demargination b) medications c) acute stressful conditions d) counter-regulatory hormones (catecholamine, cortisol) e) stimulation of immune system. ${ }^{9}$ Similarly, leukocytosis after 48 hrs may be due to hospital acquired infections. ${ }^{10}$ So, we hypothesized that leukocytes levels at 24-48 hours may be a better predictor of mortality rather than leukocytes levels at admission. Hence, in the current study, the ability of serum leukocytes levels done at admission and at 24-48 hrs of presentation to predict mortality was studied.

\section{METHODS}

This is a hospital-based, retrospective cohort study conducted at Manipal Teaching Hospital, Pokhara from January 2015 to December 2017. Study was carried out after obtaining approval from institutional review committee of the hospital. Records of all patients who were admitted in the hospital with the diagnosis of OP poisoning were obtained from medical record department of the hospital. The necessary variables were extracted and entered in a predesigned pro forma. The records with history of unknown poisoning, and poisoning with mixed compounds were excluded from study. Statistical package for the social sciences (SPSS) version 16.0 was used for statistical analysis. Quantitative variables of groups were given as arithmetic averages $\pm S D$, whereas qualitative variables were given as percentages. Independent sample $T$ test was used to assess for statistical difference in relevant continuous variables between patients who survived and those who did not. We performed logistic regression analysis keeping outcome (Mortality Vs Improvement) as dependent variable and leukocytes levels at admission and 24-48 hrs as independent variables. All P-values were considered significant if $<0.05$.

\section{RESULTS}

Total records of 103 cases who presented to Manipal Teaching Hospital over the period of two years were studied. The age (mean=29.40; $S D=11.68$ ) of the patients ranged from 15 to 60 years. Out of total 103 patients 59 (57.3\%) were females while $44(42.7 \%)$ were males. The intention for poisoning is presented in table 1:

\section{Table 1: Total number of cases and intention for poisoning}

\begin{tabular}{cc}
\hline Intention for poisoning & Total number of cases (\%) \\
\hline Suicidal & $82(79.6 \%)$ \\
Accidental & $8(7.8 \%)$ \\
Homicidal & $5(4.9 \%)$ \\
Recreational & $2(1.9 \%)$ \\
unknown & $6(5.8 \%)$ \\
\hline
\end{tabular}

Nausea/vomiting were the most common presenting symptoms. Other common symptoms were features of hyper secretions, altered sensorium and shortness of breath. All presenting symptoms are summarized in table 2 :

Table 2: Presenting symptoms

\begin{tabular}{cc}
\hline Presenting symptoms & Number of cases (\%)* \\
\hline Nausea/Vomiting & $69(67 \%)$ \\
Hyper secretions & $38(36.9 \%)$ \\
Altered sensorium & $22(21.4 \%)$ \\
Shortness of breath & $15(14.6 \%)$ \\
Pain abdomen & $13(12.6 \%)$ \\
Unconsciousness & $12(11.7 \%)$ \\
Fasciculation & $8(7.8 \%)$ \\
seizure & $5(4.9 \%)$ \\
\hline
\end{tabular}

*the total percentage exceeds 100 because of multiple symptoms being present in the same patient.

Out of total 103 patients 82 patients improved with the treatment, 14 patients died while seven left the hospital against medical advice. Nine (64.3\%) out of 14 mortality were male patients while five $(35.7 \%)$ were females.

Independent sample T test was used to assess if any difference was present in various clinical parameters in patients who died and those who improved. The data of the patients who went on leave against medical advice (LAMA) were not included in the analysis, since the outcomes of these patients were unknown. Data of leukocytes levels at 24-48 hrs in 6 of our patients and random blood sugar (RBS) of 3 of our patients were not found in the records so they were also excluded from analysis. The differences in various parameters of cases who improved and who died are shown in table 3 : 
Table 3: Independent sample T test

\begin{tabular}{|c|c|c|c|}
\hline Parameters & Improved & Mortality & P-value \\
\hline Age(yrs) $(n=96)$ & $\begin{array}{c}27.22 \text { (SD } \\
9.068)\end{array}$ & $\begin{array}{c}43.57 \text { (SD } \\
16.426)\end{array}$ & $<0.001$ \\
\hline $\begin{array}{l}\text { Systolic BP (mmHg) } \\
(\mathrm{n}=96)\end{array}$ & $\begin{array}{c}109.10 \\
(S D 15.432)\end{array}$ & $\begin{array}{c}90.57(\mathrm{SD} \\
6.394)\end{array}$ & $<0.001$ \\
\hline $\begin{array}{l}\text { Diastolic BP (mmHg) } \\
(\mathrm{n}=96)\end{array}$ & $\begin{array}{c}70.37 \text { (SD } \\
10.778)\end{array}$ & $\begin{array}{c}55.71(\mathrm{SD} \\
7.559)\end{array}$ & $<0.001$ \\
\hline $\begin{array}{l}\text { Leukocytes levels } \\
\text { (admission) ( } n=96)\end{array}$ & $\begin{array}{c}12443.41 \\
\text { (SD4369.328) }\end{array}$ & $\begin{array}{c}14679.29(S D \\
6416.757)\end{array}$ & 0.104 \\
\hline $\begin{array}{l}\text { Leukocytes levels (24- } \\
48 \mathrm{hr})(\mathrm{n}=90)^{*}\end{array}$ & $\begin{array}{l}9459.47 \text { (SD } \\
2364.892)\end{array}$ & $\begin{array}{c}17128.57 \text { (SD } \\
3249.717)\end{array}$ & $<0.001$ \\
\hline $\operatorname{RBS}(n=93)^{* *}$ & $\begin{array}{c}105.71 \text { (SD } \\
22.349)\end{array}$ & $\begin{array}{c}161.07 \text { (SD } \\
63.721)\end{array}$ & $<0.001$ \\
\hline
\end{tabular}

*Data of 6 patients were missing hence not included in the analysis

** Data of 3 patients were missing hence not included in the analysis

We applied binary logistic regression keeping outcome (Mortality vs. Improvement) as dependent variable. Leukocytes levels at admission and 24-48 hours were kept as independent variables to test the hypothesis that these levels could predict mortality. Because of relatively small sample size, other relevant factors e.g. age, sex, RBS were not included in the model. The model explained for around $48 \%$ of variance in mortality (Cox \& Snell $R^{2}=0.478$ ). Our analysis suggested that leukocytes levels at 24-48 hrs $(B=0.002, p=0.013)$ was a better predictor of mortality than Leukocytes levels at admission $(B=0.000, p=$ 0.034 ) as shown in table 4 :

\section{Table 4: Binary logistic regression}

\begin{tabular}{lcccc}
\hline Variables & B & SE & Wald & P-value \\
\hline Constant & -18.63 & 7.311 & 6.494 & 0.011 \\
$\begin{array}{l}\text { Leukocytes levels } \\
\text { (admission) }\end{array}$ & 0.000 & 0.000 & 4.484 & 0.034 \\
$\begin{array}{l}\text { Leukocytes levels } \\
\text { (24-48 hrs) }\end{array}$ & 0.002 & 0.001 & 6.182 & 0.013 \\
\hline
\end{tabular}

\section{DISCUSSION}

A retrospective analysis of 103 patients presenting to tertiary care centre of western region of Nepal was carried out. Current study describes socio-demographic variables, clinical presentation and certain lab values in those presenting patients. OP poisoning was found to be more common in female patients. It may be because, in Nepal, Indoor as well as outdoor workers are predominantly females. This may also be due to emotional vulnerability and low ability to cope with stress in female patients than in males. The patriarchal society may also be responsible to some extent for this result since similar observation was found by previous studies which were carried out in other parts of Nepal. ${ }^{11,12,13}$

As seen in table 1, consumption of OP compound with suicidal intention was found to be the most common which was also shown by many other studies. ${ }^{14,15,16,17,18}$ However, some patients in our study consumed organophosphates as a recreational substance along with alcohol which was quite different and interesting purpose of consuming it. Nausea/vomiting were the most common presenting features as shown in table 2; but these are non specific symptoms. So we have to look for other clinical features also like hyper secretions, muscle fasciculation, shortness of breath, delirium and loss of consciousness.

When we compared various demographic, clinical and lab parameters in table $\mathbf{3}$, statistically significant difference was seen in the Age, BP, RBS and Leukocytes levels (24-48 hrs) between patients who improved and those who died. However, leukocytes levels at admission were not statistically different in these two groups. The age of the patients who died was statistically significantly higher $\mathrm{p}<0.001$ ) than the age of the patients who survived. Similarly statistically significantly lower BP (both SBP and DBP) was seen in people who died. RBS on admission was higher in those patients who expired than those who Improved; and this was statistically significant $(p<0.001)$. Another study ${ }^{5}$ also found that higher blood sugar level was found in higher grades of organophosphorus poisoning. Hyperglycemia may be a result of excess counter regulatory hormones, and adrenergic influences on metabolism causing glycogenolysis. Organophosphates can also induce hyperglycemia, glucose intolerance and inhibition of insulin secretion as well.

Leukocytosis is a common finding in organophosphates poisoning. Many previous studies have found that increase in leukocytes level parallel the severity of the poisoning. Amanvermez et $\mathrm{al}^{5}$ considered leukocytes level at admission can be considered as a prognostic marker. The rise in leukocytes level on admission seems basically due to the increase in the sympathetic activity. The increase in leukocytes level can also be explained by the simultaneous cholinergic stimulation and acute inflammation due to poison. ${ }^{19,20,21}$ So in our study we have compared the WBC level at admission with the leukocytes level done at 24-48 hours and found that leukocytes at 24-48 hrs was a better predictor of mortality than leukocytes at admission as shown in table 4. 


\section{Limitation}

Following limitations of our study deserves mention. Firstly, because of the retrospective nature, our study is limited to analysis of secondary sources of information based on the hospital record files. Secondly, the data of all the patients were not available and third yet most importantly; the sample size of current study was relatively modest. Hence multivariate analyses for other significant variables were not done. Further studies in this area which improve on the current limitations are recommended.

\section{CONCLUSION}

Our study showed statistically significant difference in Age, RBS level, BP, leukocytes level at 24-48 hrs between patients who improved or died following OP poisoning; however leukocytes level at admission was not statistically significantly different in these groups. Regression analysis suggested leukocytes level

\section{REFERENCES}

1. du Toit PW, Müller FO, van Tonder WM, Ungerer MJ. Experience with the intensive care management of organophosphate insecticide poisoning. S Afr Med J. 1981; 60(6):227-9.

2. Bardin PG, van Eeden SF, Moolman JA, Foden AP, Joubert JE. Organophosphate and carbamate poisoning. Arch Intern Med. 1994; 154(13):1433-41.

3. Aaron CK, Goldfrank LR, Bresnitz EA, Kirsten RH, Howland $M A$. Insecticides: Organophosphates and Carbamates. In: Goldfrank's Toxicological Emergency, $4^{\text {th }}$ Edition, USA: Appleton \& Lange. 1990. p. $679-89$.

4. Sungurtekin H, Gürses E, Balci C. Evaluation of several clinical scoring tools in organophosphate poisoned patients. Clin Toxicol. 2006; 44(2):121-6.

5. Amanvermez R, Baydin A, Yardan T, Basol N, Gunay M. Emergency Laboratory abnormalities in suicidal patients with Acute Organophosphate Poisoning. Turk J Biochem. 2010; 35 (1):29-34.

6. Senanayake N, De Silva HJ, Karalliedde L. A scale to assess severity in organophosphorus intoxication: POP scale. Hum Exp Toxicol. 1993; 12(4):297-9.

7. Guven M, Dogukan A, Taskapan H, Cetin M. Leukocytosis as a parameter in management of organophosphate intoxication. Turk J Med Sci. 2000; 30(5):499-500. at 24-48 hrs was better predictor of mortality than leukocytes level at admission.

\section{Recommendation}

Our study recommends to get the patient's leukocytes level at 24 to $48 \mathrm{hrs}$ to predict the outcome better since leukocytosis at admission is multifactorial. However further studies with a prospective design are recommended to confirm or refute our study.

\section{Acknowledgements}

We would like to express our sincere thanks to Dr Prakash Thapa for his contribution in statistical analysis. We acknowledge all our staff at medicine department for their timely assistance and also the staff of medical record department for their help in collecting the data.

8. Singh S, Bhardwaj U, Verma SK, Bhalla A, Gill K. Hyperamylasemia and acute pancreatitis following anticholinesterase poisoning. Hum Exp Toxicol. 2007; 26(6):467 -71 .

9. Dhabhar FS, Mcewen BS. Acute stress enhances while chronic stress suppresses cell-mediated immunity in vivo: A potential role for leukocyte trafficking. Brain Behav Immun. 1997; 11(4):286-306.

10. Garner JS, Jarvis WR, Emori TG, Horan TC, Hughes JM. CDC definitions for nosocomial infections. Am J Infect Control. 1988; 16(3):128-40.

11. Karki P, Hansdak SG, Bhandari S, Shukla A, Koirala S .A clinico-epidemiological study of organophosphorus poisoning at a rural-based teaching hospital in eastern Nepal. Trop Doct. 2001; 31(1): 32-4.

12. Bhattarai N, Rauniyar A, Chaudhary D, Jaiswal S, Banthia $P$, Rana BB. Patterns of organophosphorous poisoning attending a teaching hospital. J Nepal Med Assoc. 2006; 45(162):228-32.

13. Kar SM, Timsinha S, Agrawal P. An Epidemiological study of Organophosphorus Poisoning at Manipal Teaching Hospital, Pokhara, Nepal. J Indian Forensic Sci. 2010; 32(2): 108-9.

14. Ali P, Anwer A, Bashir B, Jabeen R, Haroon H, Makki K. Clinical pattern and outcome of organophosphorus poi- 
soning. J Liaq Uni Med Health Sci. 2012; 11(1):15-8.

15. Prasad DR, Jirli PS, Mahesh M, Mamatha S. Relevance of plasma cholinesterase to clinical findings in acute organophosphorous poisoning. Asia Pac J Med Toxicol. 2013; 2(1):23-7.

16. Faiz MS, Mughal S, Memon AQ. Acute and late complications of organophosphate poisoning. J Coll Physicians Surg Pak. 2011; 21(5):288-90.

17. Gunnell D, Eddleston M, Phillips MR, Konradsen F. The global distribution of fatal pesticide self-poisoning: systematic review. BMC public health. 2007; 7(1):357.

18. Haider S, Haider I Deliberate self-harm. Pak J Med Sci. 2001.17: 151-55.
19. Clark RF. Insecticides: Organic phosphorus compounds and carbamates. In: Goldfrank's Toxicological Emergencies, $7^{\text {th }}$ Ed: The McGray-Hill companies. 2002. p. 134657.

20. Schrickel JW, Lewalter T, Lüderitz B, Nickenig G, Klehr $\mathrm{HU}$, Rabe C. Recovery from ultra-high dose organophosphate poisoning after "in-the-field" antidote treatment: Potential lessons for civil defense. J Emerg Med. 2009; 37(3):279-82.

21. Ikizceli I, Yurumez Y, Avsaroullari L, Kucuk C, Sozuer EM, Soyuer I et al. Effect of interleukin-10 on pancreatic damage caused by organophosphate poisoning. Regul Toxicol Pharmacol. 2005; 42(3):260-4. 